А. А. Дмитрук

ЛОКАЛЬНО АДЕКВАТНІ ДУО-КІЛЬЦЯ ЯК УЗАГАЛЬНЕННЯ АДЕКВАТНИХ СПРАВА КІЛЕЦЬ

Досліджено локально адекватні справа дуо-кільия, показано зв'язок між адекватними та акуратними елементами в дуо-області Безу. Доведено, шо дуо-область Безу локально адекватна тоді $і$ тільки тоді, коли для будь-яких

$\mathrm{a}, \mathrm{b} \in \mathrm{R}$, таких, шуо $\mathrm{aR}+\mathrm{bR}=\mathrm{R}$, один з иуихелементів є адекватним.

Хелмер першим почав розглядати адекватні області, щоб отримати абстрактну характеризацію кільця цілих фуункцій. Адекватні кільця 3 дільниками нуля в радикалі Джекобсона вивчав Капланський. Гілман і Хенріксен виявили, що регулярне в сенсі фон Неймана кільце є адекватним. Перший приклад неадекватної області Безу, яка є областю елементарних дільників, навів Хенріксен.

Гаталевич започаткував вивчення некомутативних адекватних кілець та їхніх узагальнень. Він довів, що узагальнено-адекватна справа дуо-область Безу є областю елементарних дільників [8].

Дуо-кільця ввели Феллер [7] і Т'єрін [11]. Тривіальними їх прикладами є, звичайно, комутативні кільця і кільця дільників нуля. Деякі цікаві випадки дуо-кілець дослідили Аусландер і Гольдман [4], зокрема, встановили існування некомутативних максимальних порядків, які є одночасно дуокільцями і нетеровими областями. Такі кільця досліджував також Маурі [9].

Всі розглянуті в статті кільця є асоціативними 31 , причому $1 \neq 0$.

Означення 1. Кільце $\mathrm{R}$ називають правил (лівим) дуо-кільием, якщо виконуються такі еквівалентні умови:

(1) кожен правий (лівий) ідеал в $\mathrm{R} \in$ ідеалом;

(2) для кожного $x \in R, R x \subset x R(R x \supset x R)$.

Праве i ліве дуо-кільця називають дуо-кільцями.

Близькими до них є абелеві кільця.

Означення 2. Кільце $\mathrm{R}$ називають абелевил, якщо для будь-якого ідемпотента $\mathrm{e}=\mathrm{e}^{2} \in \mathrm{R}$ виконується умова $\mathrm{ae}=\mathrm{ea}$, для кожного елемента $\mathrm{a} \in \mathrm{R}$. Іншими словами, будь-який ідемпотент $\mathrm{e}=\mathrm{e}^{2}$ кільця $\mathrm{R} \in$ центральним.

Варто зауважити, що клас абелевих кілець містить клас правих (лівих) дуо-кілець. Справді, нехай $\mathrm{e}=\mathrm{e}^{2} \in \mathrm{R}$ i $\mathrm{a} \in \mathrm{R}$. Згідно з означенням дуо-кільця, отримаємо рівність еа = a'e для деякого елемента $\mathrm{a}^{\prime} \in \mathrm{R}$. Тоді матимемо рівність еa $=\left(a^{\prime} e\right) e=$ еаеi симетрично $a=$ eae. Звідси одержимо, що ea $=$ ae .

Означення 3. Елемент $\mathrm{a} \neq 0$ області Безу $\mathrm{R}$ називають адекватним справа, якщо для будь-якого елемента $\mathrm{b} \in \mathrm{R}$ знайдуться такі елементи $r, s \in R$, що:

(1) $a=r \cdot s$;

(2) $b R+r R=R$;

(3) $\forall s^{\prime} \in R, S R \subset s^{\prime} R \neq R \Rightarrow b R+s^{\prime} R \neq R$.

Означення 4. Кільце, в якому кожен ненульовий елемент є адекватним справа, називають адекватним справа.

Кільце R, в якому кожен елемент є адекватним справа, зокрема і 0, називають всюди адекватним справа.

ISSN 1810-3022. Прикл. проблеми мех. і мат. - 2018. - Вип. 16. - С. 39- 42. 
Очевидним прикладом всюди адекватного справа кільця є абелеворегулярне кільце [2].

Кільце $\mathrm{R}$ називають регулярним за фон Нейманом, якщо для будьякого ненульового $a \in R$ існує такий $x \in R$, що $a x a=a$. Кільце $R$ називають локальним регулярним, якщо для кожного його елемента $a \in R$ хоча б один з елементів а або 1-а є регулярний. За аналогією можна ввести означення локально адекватного справа кільця.

Означення 5. Кільце $R$ називають локально адекватним справа, якщо для кожного його елемента $a \in R$ хоча б один з елементів а або $1-a \in$ адекватним справа.

Зрозуміло, що кожне адекватне справа кільце є локально адекватним справа. Узагальнення прикладу Хенріксена є прикладом локально адекватного справа кільця, яке не є адекватним справа:

$$
R=\left\{d_{0}+a_{1} x+a_{2} x^{2}+\ldots+a_{n} x^{n}+\ldots \mid d_{0} \in D, a_{i} \in Q\right\},
$$

де $\mathrm{D}$ - дуо-область Безу, a Q - тіло дробів.

Tвердження 1. Дуо-область Безу $\mathrm{R} \in$ локально адекватною справа тоді i тільки тоді, коли для кожних $a, b \in R$, таких, що $a R+b R=R$, один з елементів a або $\mathrm{b}$ є адекватним справа.

Д о в е д е н н я. Необхідність очевидна. Доведемо достатність.

Нехай $\mathrm{R}$ - локально адекватне справа кільце $\mathrm{i} a \mathrm{R}+\mathrm{bR}=\mathrm{R}$ для $\mathrm{a}, \mathrm{b} \in \mathrm{R}$. Тоді існують такі $u, v \in R$, що $a u+b v=1$. Враховуючи обмеження, накладене на кільце $\mathrm{R}$, то au, або bv є адекватними справа. Оскільки множина адекватних справа елементів є насиченою і мультиплікативно замкненою [12], то a або b є адекватними справа, як дільники au або bv.

Кажемо, що елемент $\mathrm{x}$ кільця $\mathrm{R} \in$ чистим, якщо $\mathrm{x}=\mathrm{u}+\mathrm{e}$, де $\mathrm{u} \in \mathrm{R}-$ оборотний елемент кільця $\mathrm{R}, \mathrm{a} \quad \mathbf{e} \in \mathbf{R}$ - ідемпотент. Кільце називають чистим, якщо кожен його елемент є чистим. Елемент $\mathrm{x}$ кільця $\mathrm{R}$ називають акуратним, якщо фактор-кільце $R / a R$ є чистим.

За аналогією з [14], якщо а є адекватним елементом дуо-області Безу $\mathrm{R}$, тоді $\mathrm{R} / \mathrm{aR}$ є напіврегулярним кільцем. Оскільки дуо-кільця є абелевими, а поняття кілець з властивістю заміни та чистих для абелевих кілець збігаються, то отримаємо такий результат.

Твердження 2. Будь-який адекватний справа елемент дуо-області Безу є акуратним справа.

Кільце $R$ називають кільцем акуратного рангу 1 , якщо $3 \mathrm{aR}+\mathrm{bR}=\mathrm{R}$, $a, b \in R$ випливає існування такого елемента $t \in R$, що $a+b t \in$ акуратним елементом кільця $\mathrm{R}$. Аналогічно, кільце $\mathrm{R}$ називають кільцем адекватного рангу 1, якщо з $a R+b R=R, a, b \in R$ випливає існування такого елемента $\mathrm{t} \in \mathrm{R}$, що $\mathrm{a}+\mathrm{bt} \in$ адекватним елементом кільця $\mathrm{R}$.

Tеорема 1. Стабільний ранг адекватного справа дуо-кільця Безу не перевищує 2.

Д о в е д е н н я. Див. [1, теорема 1].

Нагадаємо, що кільце має стабільний ранг 1 (у позначеннях cm.p. $(\mathrm{R})=1$ ), якщо для таких довільних елементів $a, b \in R$, що $a R+b R=R$, існує такий елемент $x \in R$, що $(a+b x) R=R$ [10]. Враховуючи результати праць $[3,6$, 13], як очевидний наслідок отримали такі теореми.

Tеорема 2. Всюди адекватне дуо-кільце Безу є кільцем елементарних дільників.

Tеорема 3. Всюди адекватне дуо-кільце Безу є кільцем з елементарною редукцією матриць. 
Теорема 4 [5]. Нехай R - дуо-кільце. Наступні властивості еквівалентні:

1) $\mathrm{R}$ - кільце з властивістю заміни;

2) $\mathrm{R}$ - чисте кільце;

3) $\mathrm{R}$ - кільце ідемпотентного стабільного рангу 1.

Покажемо, що всюди адекватне дуо-кільце Безу є чистим.

Tеорема 5. Всюди адекватне дуо-кільце Безу є кільцем ідемпотентного стабільного рангу 1.

Д о в е д е н н я. Див. [1, теорема 16]. Як наслідок отримаємо такі результати.

Теорема 6. Всюди адекватне дуо-кільце Безу є кільцем з властивістю заміни.

Теорема 7. Всюди адекватне дуо-кільце Безу є чистим.

Tеорема 8. Локально адекватне кільце є кільцем адекватного рангу 1.

Д о в е д е н н я. Нехай $R$ - локально адекватне кільце $\mathrm{i} a \mathrm{R}+\mathrm{bR}=\mathrm{R}$, $a, b \in R$. Якщо a адекватний елемент $R$, тоді, очевидно, $a+b \cdot 0$ є адекватним елементом $R$. Якщо ж a не $\epsilon$ адекватним елементом $R$, розглянемо елемент $\mathrm{a}+\mathrm{b}$. Оскільки $\mathrm{aR}+(\mathrm{a}+\mathrm{b}) \mathrm{R}=\mathrm{R}$ з твердження 2 , тоді $\mathrm{a}+\mathrm{b}$ є адекватним елементом кільця $\mathrm{R}$.

Tеорема 9. Дуо-область Безу є областю елементарних дільників тоді і тільки тоді, коли вона є кільцем акуратного рангу 1.

Теорема 10. Будь-яка дуо-область Безу адекватного рангу 1 є кільцем елементарних дільників.

Д о в е д е н н я. Нехай R - дуо-кільце адекватного рангу 1. Це означає, що $3 \mathrm{aR}+\mathrm{bR}=\mathrm{R} \quad(\mathrm{a}, \mathrm{b} \in \mathrm{R})$ випливає існування такого елемента $t \in R$, що $a+b t=\alpha$ є адекватним елементом $R$. Оскільки адекватні елементи є акуратними, $\mathrm{R} / \alpha \mathrm{R}$ є чистим кільцем. За теоремою 9, $\mathrm{R}$ є кільцем елементарних дільників.

Теорема 11. Локально адекватна дуо-область Безу є кільцем елементарних дільників.

Д о в е д е н н я. За теоремою 8, будь-яке локально адекватне кільце $\mathrm{R} \in$ кільцем адекватного рангу 1 . За теоремою $10, \mathrm{R} \in$ кільцем елементарних дільників. Отже, теорему доведено.

1. Васюник I. С., Забавсъжий Б. В. Стабільний ранг адекватного дуо-кільця Безу та його узагальнення // Прикл. проблеми механіки і математики. - 2011. - 9. C. 69- 73.

2. Гаталевич A. I. Про адекватні і узагальнено адекватне дуо-кільце і дуо-кільце елементарних дільників // Мат. студії. - 1998. - 9, № 2. - С. 115- 119.

3. Забавсъкий Б. В., Романів О. М. Кільця з елементарною редукцією матриць // Укр. мат. журн. - 2000. - 52, № 2. - С. 1641- 1649.

4. Auslander M., Goldman O. Maximal orders // Trans. Amer. Math. Soc. - 1960. 97. - P. 1- 24.

5. Camillo V., Yu H. P. Exchange rings, units and idempotents // Comm. Algebra. 1994. - 22 (12). - P. 4737-4749.

6. Cohn P. On the structure of the GL2 of a ring // Publ. Math. I.H.E.S. - 1966. - 30. - P. 5- 59.

7. Feller E. Properties of primary noncommutative rings / / Trans. A mer. Math. Soc. 1958. - 89. - P. 79- 91.

8. Gatalevych A. On adequate and generalized adequate duo-rings and elementary divisor duo-rings. // Math. Stud. - 1998. - 9. - P. 115- 119. 
9. Maury G. Characterisation des ordres maximaux // C. R. Acad. Sc. Paris, Ser. A. 1969. - 269. - P. 993- 996.

10. Nicholson W. Lifting idempotents and exchange rings // Trans. Amer. Math. Soc. 1977. - 239. - P. 269- 278.

11. Thierrin G. On duo rings // Canad. Math. Bull. - 1960. - 3. - P. 167- 172.

12. Zabavsky B. A sharp Bezout domain is an elementary divisor rings // Ukr. Math. J . - 2014. - 66 (2). - P. 316- 321.

13. Zabavsky B. Diagonalization of matrices over ring with finite stable rank // Вісник Львівськ. нац. ун-ту. - 2003. - 61. - Р. 206- 210.

14. Zabavsky B. V., Bilyavska S. I. Weakly global dimention of finite homomorphic images of commutative Bezout domain // Appl. Problems Mech. Math. - 2012. 10. - P. 71- 73 .

ЛОКАЛЬНО АДЕКВАТНЫЕ ДУО-КОЛЬЦА

КАК ОБОБЩЕНИЕ АДЕКВАТНЫХ СПРАВА КОЛЕЦ

Исследованъ локально правые адекватные дуо-кольиа, указана связъ между правъми адекватныли и аккуратными әлементами в дуо-области Безу. Доказано, что дуо-область Безу будет локально правой адекватной тогда и только тогда, когда для любых $\mathrm{a}, \mathrm{b} \in \mathrm{R}$, таких, что $\mathrm{aR}+\mathrm{bR}=\mathrm{R}$, один из этих әлементов является правым адекватнъм.

\section{LOCALLY ADEQUATE DUO RINGS}

AS A GENERALIZATION CASE OF RIGHT ADEQUATE RINGS

A locally right adequate duo-rings have been investigated, the relation between right adequate elements and neat elements in the duo Bezout domain has been shown. It has been proved that the Bezout duo domain is locally right adequate if and only if for any $a, b \in R$ such that $a R+b R=R$, one of these elements is right adequate.

Львів. нац. ун-т

Одержано

ім. Івана Франка, Львів

06.11 .18 